\title{
Carcinoma de células renais papilífero tipo 2 de apresentação infrequente: relato de caso
}

\author{
Carcinoma of renal papillary type 2 cells of infrequent presentation: case report
}

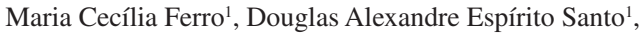
André Luís Bettiati ${ }^{1}$, Marcelo Welker Sapojkin Rossine ${ }^{1}$

\begin{abstract}
RESUMO
Os carcinomas de células renais (CCRs) compreendem de 1 a 3\% de todas as neoplasias malignas viscerais e são mais prevalentes em pacientes do sexo masculino. No Brasil, a incidência dessa neoplasia varia entre 7 e 10 casos por 100 mil habitantes por ano nas áreas mais industrializadas. O tabagismo é um fator de risco definitivo para o CCR. Outros fatores relacionados, porém não esclarecidos definitivamente, incluem obesidade, hipertensão arterial e terapêutica com estrogênios. Os CCRs, em suas fases iniciais, não manifestam sinais ou sintomas característicos, o que dificulta seu diagnóstico precoce. Mais de $60 \%$ dos casos de tumores renais são diagnosticados incidentalmente durante realização de exames de imagem, principalmente em decorrência da utilização crescente da ultrassonografia e da tomografia computadorizada. Cerca de 70 a 80\% dos CCRs são carcinomas de células claras. Tumores papilares aparecem em 10 a $15 \%$ dos casos e tumores cromófobos, em cerca de 3 a $5 \%$. Essa classificação histológica é extremamente importante por determinar significativas implicações prognósticas e terapêuticas. O presente artigo objetivou apresentar o relato de um caso de carcinoma renal papilífero de tipo 2, diagnosticado em paciente do sexo feminino, com grandes dimensões e padrão predominantemente cístico, variantes infrequentes dos CCRs.

Palavras-chave: carcinoma de células renais; carcinoma papilar; neoplasias renais.
\end{abstract}

\begin{abstract}
Renal cell carcinomas (RCC) represent 1 to $3 \%$ of all malignant visceral neoplasms and are more prevalent in male patients. In Brazil, the incidence of this cancer varies between 7 to 10 cases per 100 thousand inhabitants per year in industrialized regions. Smoking is a definitive risk factor for RCC. Other related factors, but not definitely confirmed, can be related, as obesity, hypertension and therapy with estrogens. The RCCs, in their initial phases, do not manifest characteristic signs or symptoms, which hinders early diagnosis. More than $60 \%$ of kidney tumors cases are diagnosed incidentally during routine imaging examinations, mainly due to the increasing use of ultrasonography (US) and computed tomography (CT). About 70 to $80 \%$ of RCCs are clear cell carcinomas. Papillary tumors represent 10 to $15 \%$ of cases, and chromophobe tumors, about 3 to 5\%. This histological classification is extremely important, because it determines significant prognostic and therapeutic implications. The present article presents the case report of a papillary type 2 renal cells carcinoma, diagnosed in a female patient, with large size and predominantly cystic pattern, infrequent variants of renal cell carcinomas.
\end{abstract}

Keywords: carcinoma, renal cell; carcinoma, papillary; kidney neoplasms.

\section{INTRODUÇÃO}

Os carcinomas de células renais (CCRs) compreendem de 1 a $3 \%$ de todas as neoplasias malignas e são mais prevalentes em pacientes do sexo masculino. Cerca de $40 \%$ dos pacientes com CCR morrem devido à progressão da doença ${ }^{1}$ e aproximadamente $20 \%$ dos pacientes se apresentam com metástases no momento do diagnóstico de CCR. Os locais mais frequentes de metástases a distância são: pulmões, ossos, fígado e cérebro. ${ }^{2}$

No Brasil, a incidência dessa neoplasia varia entre 7 e 10 casos por 100 mil habitantes por ano nas áreas mais industrializadas, com taxas menores em regiões menos desenvolvidas. Por esse motivo, não há justificativa para rastreamento populacional com a finalidade de diagnosticar precocemente os casos de CCR. ${ }^{3}$

${ }^{1}$ Pontifícia Universidade Católica de São Paulo, Faculdade de Ciência Médicas e da Saúde - Sorocaba (SP), Brasil.

Autor correspondente: Douglas Alexandre Espírito Santo - Rua Catuipe, 158 - Parque Novos Estados - CEP: 79034-034 -

Campo Grande (MS), Brasil - E-mail: douglasalexandre18@gmail.com

Recebido em 15/07/2016. Aceito para publicação em 22/07/2017. 
O tabagismo é um fator de risco definitivo para o CCR, pois duplica a chance de desenvolvimento desse tumor e contribui com, pelo menos, um terço de todos os casos. Outros fatores relacionados, porém não esclarecidos definitivamente, incluem obesidade, hipertensão arterial, exposição a cádmio, derivados da gasolina e do chumbo, irradiações e terapêutica com estrogênios. ${ }^{4,5}$

Os CCRs, em suas fases iniciais, não manifestam sinais ou sintomas característicos, o que dificulta seu diagnóstico precoce. Recentemente, essas neoplasias têm sido mais encontradas ocasionalmente em exame clínico de rotina, cirurgias abdominais ou exames de imagem para outras finalidades. ${ }^{6,7}$ A tríade clássica dor lombar, hematúria e massa palpável no flanco é vista em menos de $10 \%$ dos casos. Por essa razão, mais de $60 \%$ dos casos de tumores renais são diagnosticados incidentalmente durante realização de exames de imagem, principalmente em decorrência da utilização crescente da ultrassonografia (US) e da tomografia computadorizada (TC). ${ }^{4,5}$ A classificação de Bosniak é boa preditora da probabilidade de malignidade dos cistos renais visualizados em tomografias.

Recentemente, diversos estudos estabeleceram correlações entre a classificação histológica dos CCRs e os achados por métodos de imagem, tornando importante o esforço do radiologista na tentativa de reconhecimento (por imagem) dos possíveis padrões histológicos de CCR (especialmente na diferenciação entre provavelmente de células claras ou não células claras). ${ }^{1,3,7-11}$

No entanto, a confirmação diagnóstica só é possível com a análise histopatológica, seja por biópsia, exame anatomopatológico (EAP) da peça cirúrgica após nefrectomia parcial ou radical, ou, ainda, pelo resultado de necrópsias. Ferramentas auxiliares, como a imuno-histoquímica, mostram-se muito úteis na determinação do subtipo histológico de CCR..$^{3,7,10,12}$

Os principais subtipos histológicos de tumores renais são divididos em: CCR convencional (células claras); CCR papilífero (tipos 1 e 2); CCR cromófobo; CCR dos ductos coletores (Bellini); CCR medular; CCR com translocação Xp11; carcinoma de células fusiformes e mucinosas; CCR não classificado; adenoma papilar e oncocitoma. ${ }^{1,3}$
Cerca de 70 a $80 \%$ dos CCRs são carcinomas de células claras. Tumores papilares aparecem em 10 a $15 \%$ dos casos e os tumores cromófobos, em cerca de 3 a $5 \%$. O restante é composto por tipos mais raros de neoplasia. ${ }^{4,5}$ Essa classificação histológica é extremamente importante por determinar significativas implicações prognósticas e terapêuticas. . $^{1,3,6-7}$

O presente trabalho objetivou abordar o relato de um caso de carcinoma renal papilífero de tipo 2, diagnosticado em paciente do sexo feminino, com grandes dimensões e padrão predominantemente cístico - variantes infrequentes dos CCRs.

\section{RELATO DE CASO}

Paciente do sexo feminino, 57 anos, casada, três filhos, foi admitida ambulatorialmente com queixas de anorexia, perda de peso $(3,5 \mathrm{~kg})$, dor e distensão abdominal esporádicas. Referia antecedentes de alergia a cetoprofeno, hipertensão arterial crônica e terapia de reposição hormonal por menopausa precoce, aos 43 anos. Não possuía internações anteriores e estava apenas em tratamento anti-hipertensivo com besilato de anlodipino e valsartana $5 \mathrm{mg} / \mathrm{dia}$. Após exame clínico inocente, a paciente foi submetida a US de abdome total para investigação das queixas abdominais. Esta evidenciou um cisto renal à esquerda com classificação Bosniak IV.

A nefrectomia total esquerda foi realizada três meses após o diagnóstico por imagem. No pré-operatório, a paciente se apresentou com queixas mais importantes de diminuição do apetite e do débito urinário, dor e distensão abdominal seguidas de vômito e desconforto respiratório. Referia ainda constipação intestinal e insônia. Os exames laboratoriais pré-operatórios, no entanto, não apresentaram alterações quaisquer.

Ao exame anatomopatológico observou-se o rim esquerdo pesando $1.166 \mathrm{~g}$ e medindo $16 \times 15 \times 3 \mathrm{~cm}$, com a cápsula levemente aderida. Aos cortes, observou-se área cística previamente seccionada, medindo $15 \times 13 \mathrm{~cm}$ nos maiores eixos, ocupada por material ora macio ora grumoso, de coloração castanho vinhoso. Na parede interna, notaram-se

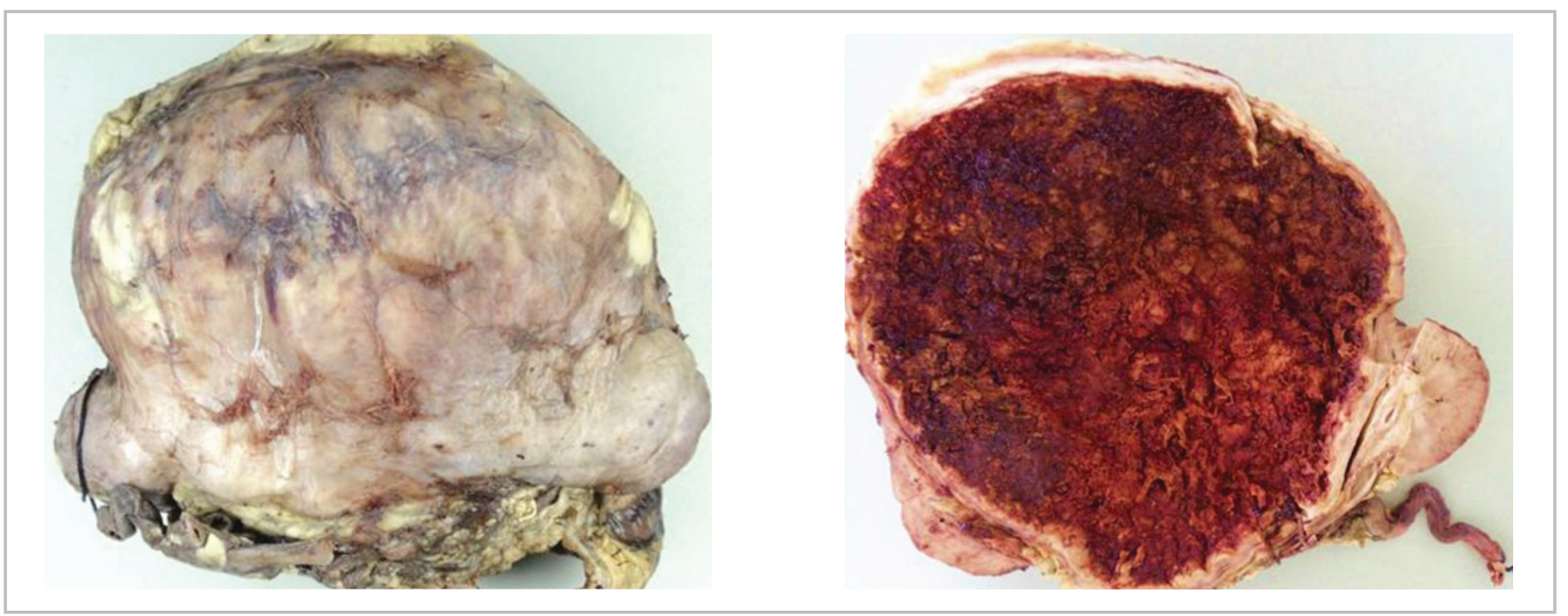

Figura 1. Rim esquerdo. 
áreas sobrelevadas de até $3 \times 2,5 \mathrm{~cm}$ de consistência firme e coloração ora vinhosa ora alaranjada (Figura 1).

A microscopia revelou diagnóstico de CCR do tipo papilar, cístico e com extensas áreas de necrose. As células caracteristicamente atípicas, com citoplasma claro e acidófilas, formavam estruturas papilares e, em alguns campos, estavam presentes estruturas acinares (Figura 2). Junto às áreas de necrose notaramse macrófagos vacuolizados e cristais de colesterol. A interpretação desses achados indicou diagnóstico de CCR papilar de tipo 2. Nas adjacências da peça cirúrgica, a pelve presente era escassa e o ureter apresentou-se dentro do padrão de normalidade.

\section{DISCUSSÃO}

Apesar de acometer mais homens que mulheres, esse caso de CCR foi observado em paciente do sexo feminino. As manifestações clínicas iniciais não nos remetiam ao diagnóstico de CCR. Assim como na maioria dos casos, este achado foi ocasionalmente encontrado por exames de imagem motivados por sintomatologia inespecífica. Os únicos fatores de risco presentes nesse caso foram hipertensão arterial crônica e antecedentes de terapia de reposição hormonal; porém, o envolvimento desses ainda não foi elucidado completamente na patogênese dos CCRs.

Geralmente, os CCRs apresentam-se com lesões primariamente sólidas e aproximadamente $40 \%$ deles possuem áreas císticas decorrentes de necrose ou hemorragia. No entanto, somente menos de 5\% dos CCRs são lesões predominantemente císticas, como neste caso.

O padrão cístico que exibe septações, contornos irregulares, nódulos murais, paredes espessas ou calcificações é altamente suspeito para CCR e deve ser estudado por outros métodos de imagem mais específicos, preferencialmente a TC. ${ }^{8,13,14}$ Nesse contexto, Bosniak, em 1986, desenvolveu um esquema de classificação baseado nos critérios de imagem fornecidos pela TC, que permite analisar os aspectos pertinentes ao contorno e conteúdo do cisto renal, à presença de septações e/ou calcificações e à avaliação do realce após a administração intravenosa do meio de contraste. Assim, é
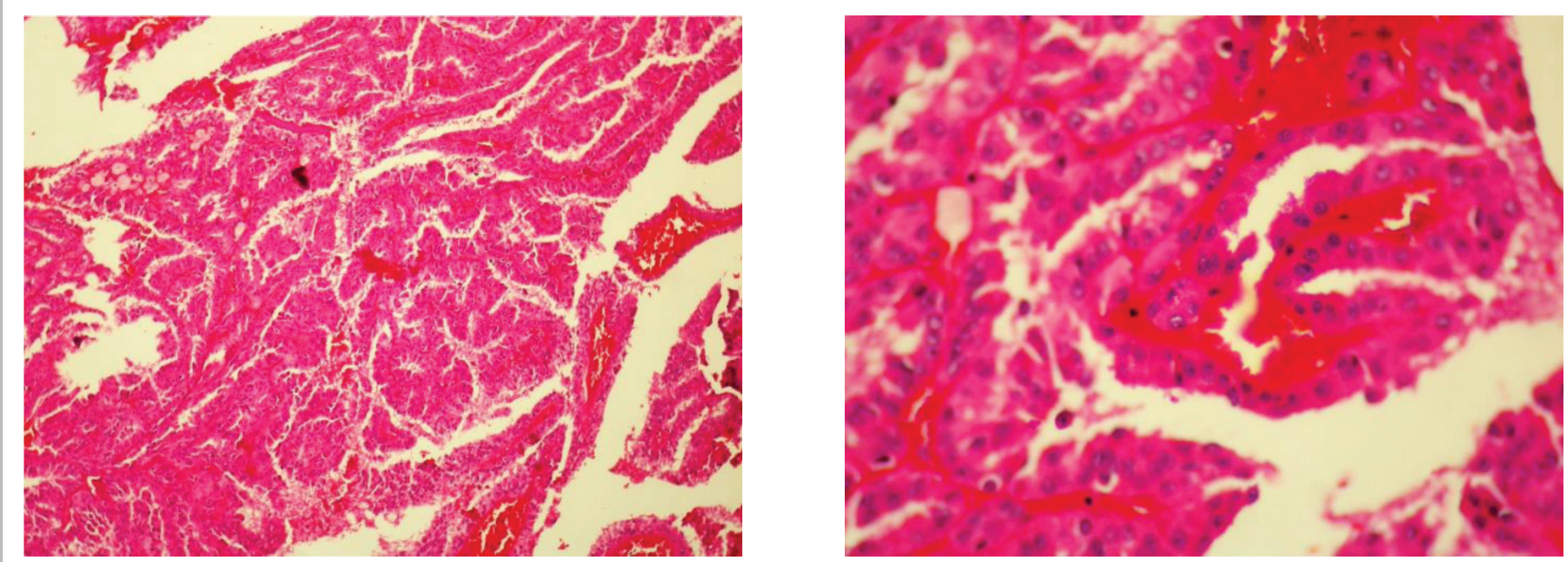

Figura 2. Lâminas histológicas de rim esquerdo em área representativa da neoplasia (Coloração HE).

Quadro 1. Classificação de lesões renais císticas, segundo Bosniak.

\begin{tabular}{|c|c|c|c|c|}
\hline Classificação & Características & $\begin{array}{l}\text { Porcentagem } \\
\text { de malignidade }\end{array}$ & Significado & Conduta \\
\hline Tipo I & $\begin{array}{l}\text { Paredes finas e regulares, sem septos ou calcificações, } \\
\text { densidade } 0-20 \text { UH, não realça com contraste }\end{array}$ & 0 & $\begin{array}{l}\text { Com certeza um } \\
\text { cisto simples }\end{array}$ & Observação \\
\hline Tipo II & $\begin{array}{l}\text { Paredes com septações finas }<1 \mathrm{~mm} \text {, calcificações line- } \\
\text { ares, regulares, cisto hiperdenso }<3 \mathrm{~cm} \text { (densidade }>20 \\
\mathrm{UH} \text { ), sem realce de contraste }\end{array}$ & 0 & $\begin{array}{l}\text { Provavelmente } \\
\text { um cisto simples }\end{array}$ & Observação \\
\hline Tipo IIF & $\begin{array}{l}\text { Similares ao tipo II, mas sem características bem } \\
\text { definidas, cistos hiperdensos }>3 \mathrm{~cm}\end{array}$ & 10 & $\begin{array}{l}\text { Cisto simples } \\
\text { complicado }\end{array}$ & $\begin{array}{l}\text { Segmento } \\
\text { constante }\end{array}$ \\
\hline Tipo III & $\begin{array}{l}\text { Paredes espessadas, septações espessas, irregulares } \\
\text { ou múltiplas, calcificaç̃es periféricas ou difusas, } \\
\text { septos realçam com contraste }\end{array}$ & 40 a 60 & $\begin{array}{l}\text { Cisto complexo: } \\
\text { pode ser cisto ou } \\
\quad \text { tumor }\end{array}$ & $\begin{array}{l}\text { Exploração } \\
\text { cirúrgica }\end{array}$ \\
\hline Tipo IV & $\begin{array}{l}\text { Paredes espessas, septos espessos, calcificações } \\
\text { grosseiras, realça com contraste, massa sólida junto } \\
\text { às paredes ou aos septos }\end{array}$ & 80 a 100 & $\begin{array}{l}\text { Provavelmente } \\
\text { neoplásico }\end{array}$ & Nefrectomia \\
\hline
\end{tabular}


possível categorizar as lesões renais císticas em ordem crescente para a probabilidade de malignidade, como mostra o Quadro 1. ${ }^{9,14}$ A conduta para cistos renais com classificação Bosniak IV é cirúrgica e foi a adotada nessa paciente.

Muitos trabalhos na literatura mundial têm mostrado diferenças no prognóstico dos diferentes tipos histológicos dos tumores renais, no tratamento e na evolução desses pacientes. Fatores como a presença de componente sarcomatoide, o grau nuclear, a presença de necrose, o tamanho do tumor e o estádio TNM estão associados com a mortalidade nos três tipos de CCRs mais frequentes (células convencionais, papilar e cromófobo). ${ }^{10,12} \mathrm{O}$ clássico trabalho de Fuhrman et al. ${ }^{11}$ demonstra que uma determinada característica histológica, no caso o grau nuclear, parece ser o critério morfológico mais significativo para o prognóstico.

Os CCRs de células claras (convencional) são o subtipo mais comum e que têm pior prognóstico, pois apenas 50\% deles estão entre os estádios I e II no momento do diagnóstico.

O CCR papilífero é um subtipo com arquitetura papilífera ou túbulo-papilífera, mais raro, e sua diferenciação do carcinoma de células claras é fundamental. Geralmente representa cerca de $10 \%$ dos CCRs. Frequentemente contém áreas de hemorragia, necrose e degeneração cística. As papilas com agregados de macrófagos espumosos são comuns e grânulos de hemossiderina podem estar presentes em macrófagos, estroma e citoplasmas das células neoplásicas. Calcificações são comuns nos eixos das papilas e no estroma desmoplásico adjacente. Alteração sarcomatoide ocorre em 5\% dos casos.

Os CCRs papilíferos de tipo 1 (basófilo) apresentam papilas e estruturas tubulares revestidas por pequenas células com citoplasmas pálidos, núcleos pequenos, ovais e nucléolos inconspícuos. Essas pequenas células têm escasso citoplasma claro e núcleos hipercromáticos. O tipo 2 (acidófilo) caracteriza-se por possuir papilas revestidas por células grandes, com citoplasmas amplos, acidófilos, núcleos pseudoestratificados, volumosos e esféricos, com nucléolos proeminentes e, geralmente, associados a áreas de necrose.

Habitualmente, à época do diagnóstico, os CCRs papilíferos de tipo 2 apresentam-se como neoplasia de alto grau, associada a metástases ganglionares e, às vezes, à invasão venosa, o que ainda não foi documentado neste caso. Mesmo assim, eles possuem pior prognóstico em relação aos de tipo 1, especialmente na presença de áreas de hemorragia, necrose e alto grau nuclear.

Este caso é, portanto, um exemplo de uma variante histológica rara do CCR e de apresentação infrequente, uma vez que foi diagnosticada em paciente do sexo feminino, possuindo grandes dimensões, característica macroscópica predominantemente cística e padrão histológico pouquíssimo frequente entre os CCRs.

\section{REFERÊNCIAS}

1. Muglia VF, Prando A. Carcinoma de células renais: classificação histológica e correlação com métodos de imagem. Radiol Bras. 2015;48(3):166-74. DOI: 10.1590/0100-3984.2013.1927

2. Marshall FF, Stewart AK, Menck HR. The National Cancer Data Base: report on kidney cancers. The American College of Surgeons Commission on Cancer and the American Cancer Society. Cancer. 1997;80(11):2167-74.

3. Wünsch-Filho V. Insights on diagnosis, prognosis and screening of renal cell carcinoma. São Paulo Med J. 2002;120:163-4. DOI: 10.1590/S1516-31802002000600001

4. Motzer RJ, Agarwal N, Beard C, Bolger GB, Boston B, Carducci MA, et al. NCCN clinical practice guidelines in oncology: kidney cancer. J Natl Compr Canc Netw. 2009;7(6):618-30.

5. Delahunt B, Eble JN. Papillary renal cell carcinoma: a clinicopathologic and immunohistochemical study of 105 tumors. Modern Pathol. 1997;10:537-44.

6. Pedroso D, Donadussi M, Mwentz M, Grazziotin RZ. Carcinoma papilífero renal em jovem. Rev Méd Hosp São Vicente de Paulo. 2000;11(26):75-6.

7. Souza OER. Neoplasias renais em nefrectomias realizadas no período de 1990 a 2006 na Universidade Federal do Triângulo Mineiro [dissertação]. Uberaba: Universidade Federal do Triângulo Mineiro; 2008.

8. McClennan BL, Stanley RJ, Melson GL, Levitt RG, Sagel SS. CT of the renal cyst: is cyst aspiration necessary? AJR Am J Roentgenol. 1979;133:671-5. DOI: 10.2214/ajr.133.4.671

9. Miranda CMNR, Maranhão CPM, Santos CJJ, Padilha IG, Farias LPG, Rocha MS. Classificação de Bosniak das lesões císticas renais segundo achados na tomografia computadorizada multidetectores. Radiol Bras. 2014;47(2):145-51. DOI: 10.1590/S010039842014000200015

10. Amin MB, Tamboli P, Javidan J, Stricker H, Venturina MP, Deshpande A, et al. Prognostic impact of histologic subtyping of adult renal epithelial neoplasms. Am J Surg Pathol. 2002;26:281-91.

11. Fuhrman SA, Lasky LC, Limas C. Prognostic significance of morphologic parameters in renal cell carcinoma. Am J Surg Pathol. 1982;6:655-63.

12. Cheville JC, Lohse CM, Zincke H, Weaver AL, Blute ML. Comparisons of outcome and prognostic features among histologic subtypes of renal cell carcinoma. Am J Surg Pathol. 2003;27:612-24.

13. Reis M, Guimarães M. Carcinoma de células renais: noções básicas. Acta Méd Port. 1999;12:81-5.

14. Charboneau JW, Hattery RR, Ernst EC 3rd, James EM, Williamson B Jr, Hartman GW. Spectrum of sonographic findings in 125 renal masses other than benign simple cyst. AJR Am J Roentgenol. 1983;140:87-94. DOI: 10.2214/ ajr.140.1.87

\section{Como citar este artigo:}

Ferro MC, Espírito Santo DA, Bettiati AL, Rossine MWS. Carcinoma de células renais papilífero tipo 2 de apresentação infrequente: relato de caso. Rev Fac Ciênc Méd Sorocaba. 2018;20(1):44-7. DOI: 10.23925/1984-4840.2018v20i1a10 